\title{
Devir-criança da Matemática: experimentações em uma pesquisa com imagens e infâncias
}

\author{
Becoming-child of Mathematic: Experimentations in a research of images \\ and childhood
}

\author{
Bianca Santos Chisté* \\ César Donizetti Pereira Leite ${ }^{* *}$ \\ Luana Priscila de Oliveira**
}

\begin{abstract}
Resumo
Este artigo apresenta-se com o propósito de refletir sobre a criança, a infância, a educação e a educação matemática. Ele parte de uma pesquisa desenvolvida em uma Escola Pública de Educação Infantil em Vilhena RO, utilizando-se da metodologia de produção de imagens por crianças. $O$ estudo parte da seguinte problemática: o que pode uma pesquisa de produção de imagens com crianças pequenas provocar a matemática, a educação matemática e a pesquisa em educação matemática a pensar? Dessa maneira, procuramos discutir, neste trabalho, a pesquisa e sua relação com a experiência, como movimento de colocarmo-nos à prova, a invenções, a experimentações de sentidos, de sensações, de saberes. Acreditamos que a pesquisa aponta uma importante discussão para a educação matemática: que seja mais atenta, que se distinga por uma atitude frente às múltiplas dimensões do aprender e que se configure em um movimento de invenção recíproca e indissociável de si-matemática e do mundo.
\end{abstract}

Palavras-chave: Infância. Pesquisa. Imagens. Experiência. Devir-Criança da Matemática.

\begin{abstract}
This article is presented for the purpose of reflecting on the child, childhood education and mathematics education. We depart from a research developed in a Public Early Childhood School in Vilhena - RO, using the images of children production methodology. The study raises the following question: What can an imaging of research production of small children provoke mathematics, mathematics education, and research in mathematics education to think? In this way, we seek to discuss the research and its relation to the experience, as a way to test ourselves, the inventions, the senses experimentation, feelings, and knowledge. We believe that the research shows an important discussion for mathematics education: that may be more watchful, which is distinguished by an attitude to the multiple dimensions of learning and that is configured in a movement of reciprocal and inseparable invention of self-mathematics and the world.
\end{abstract}

\footnotetext{
* Doutora em Educação Matemática pela Universidade Estadual Paulista (UNESP/Rio Claro). Professora da Universidade Federal de Rondônia (UNIR), Rolim de Moura, Rondônia, Brasil. Endereço para correspondência: Avenida Maceió, 4919, Centro, CEP 76984-000, Rolim de Moura, Rondônia, Brasil. E-mail: bia_chiste@yahoo.com.br

** Livre Docente em Psicologia do Desenvolvimento pela Universidade Estadual Paulista (UNESP). Professor Adjunto do Departamento de Educação da Universidade Estadual Paulista, Rio Claro, São Paulo, Brasil. Endereço para correspondência: Av. 24A no. 1515, Bela Vista, CEP 13506-900, Rio Claro, São Paulo, Brasil. Email: mevhleite@uol.com.br e cesar@rc.unesp.br .

*** Mestranda em Educação pela Universidade Estadual Paulista (UNESP/Rio Claro). Endereço para correspondência: Av. 24A no. 1515, Bela Vista, CEP 13506-900, Rio Claro, São Paulo, Brasil. E-mail: luoliveira923@yahoo.com.br.
} 
Keywords: Childhood. Research. Images. Experience. Becoming-child of Mathematics.

\section{Iniciando a conversa}

Sempre compreendo o que faço depois que já fiz. O que sempre faço, nem seja uma aplicação de estudo. É sempre uma descoberta. Não é nada procurado. É achado mesmo. (BARROS, 2010, p. 85)

Nos últimos anos, o grupo Im@go ${ }^{1}$ tem desenvolvido pesquisas na interface entre infância, cinema e educação. Nesses estudos temos observado que pesquisar com criança é um convite a um deslocamento das certezas, dos lugares seguros e previamente garantidos, muitas vezes presentes nas pesquisas no campo da educação, pois o que temos com as crianças é um processo de exposição, de afetação, de experiência; é como estar em perigo constantemente, pois nesses deslocamentos enveredamos por travessias que escapam às certezas dos experimentos, dos protocolos de pesquisas e acabamos por habitar novos tempos, lugares e espaços. Nessa perspectiva, habitar, como nos diz Gagnebin (2011, p. 60), "significa deixar rastros", povoar o mundo, a educação, a vida com marcas que singularizam a própria existência, que singularizam a pesquisa, o pesquisar e a educação. Nesse sentido, pesquisar com crianças é um convite a habitar a própria infância, pois é um convite a retornar ao tartamundo, às experiências primeiras, às experiências de fonte, onde o verbo ainda é virgem. É como criar outras vias, criar desvios naquilo que, supostamente, é apresentado pela ciência, pelo método da ciência objetiva, que constitui uma triangulação dos dados.

Pesquisar com crianças e com infância tem, então, se apresentado, em nossos estudos, como abertura e deslocamento de outros tempos e espaços, gerados no circuito de produção de imagens pelas crianças, nas paisagens vertigens, nas imagens sem legendas prévias, nos afectos que disparam, pois, ao assistirmos, aos olharmos as imagens produzidas pelas crianças, elas (crianças e imagens) sempre nos deixam algo em aberto, sempre produzem a sensação de já acabou?, sempre ficamos esperando mais. As imagens começam e terminam, fazendo lembrarmo-nos de Benjamin, quando diz "a verdadeira imagem do passado perpassa veloz. O passado só se deixa fixar, como imagem que relampeja irreversivelmente, no momento em que é reconhecido" (BENJAMIN, 1994 p. 224), ou, dizendo de outra forma, as imagens acontecem, nos acontecem e nos passam.

\footnotetext{
${ }^{1}$ Laboratório da Imagem, Experiência e Criação - UNESP Rio Claro; coordenador professor Dr. César Donizetti Pereira Leite
} 
O que vemos em nossos trabalhos é que os cortes não propositais, mas acidentais, casuais, produto de olhares rápidos, sem técnicas, repletos de perguntas, ecos e sons, deixamnos a leve sensação de abertura. É como se, ao começar a história e como se ao vermos os filmes/imagens, ficássemos esperando saber o que vem depois; a infância pela criança apresenta-nos um mundo de reticências, um mundo pontilhado de possibilidades pelo ritmo cortado, sem sentido fixo, sem sentido dado, sem sentido previsto, sem sentido. É assim que a infância aparece e parece ser para nós, como esse tempo curto e intenso, mas também como tempo presente que nos deixa abertura e espera.

Frequentemente, no campo da Pesquisa em Educação, de um modo geral, e da Pesquisa em Educação Matemática, de modo particular, o que verificamos é que, quando nos propomos a desenvolver uma pesquisa, as perguntas já devem estar postas, elaboradas, prontas. Elas seriam o ponto de partida de toda pesquisa, de todo pensamento; ditam percursos, caminhos, e, muitas vezes, apresentam-nos resultados já previamente, antecipandose às próprias perguntas. Sendo assim, fazer pesquisa cria, muitas vezes, um espaço seguro, tranquilo, certeiro, e, com isso, sentimo-nos confortados. Entretanto, como poderia uma pesquisa com crianças e com infância trazer essa suposta seguridade se as crianças e a infância apresentam-nos movimentos inesperados, falas incompletas, intercortadas e tumultuadas, imagens embaçadas, vertiginosas, um mundo onde há muito chão? Parece, então, que pesquisar com crianças, com infância é ser atravessado a todo tempo por inquietações. Uma pergunta levando a outra, e mais outra, e mais outra. Ou seja, nas pesquisas que desenvolvemos com crianças as perguntas não estão no ponto de partida do trabalho, mas atravessam o tempo todo da pesquisa, impedindo que respostas calem essa força das interrogações e fazendo com que a pesquisa aponte-nos, sempre, muitos caminhos.

Dessa maneira, parece-nos possível dizer que pesquisar com crianças não é algo que se coloca em uma origem (um lugar de origem), que pretende uma finalidade (um lugar de chegada), mas que a própria pesquisa seja espaço de travessia, desses atravessamentos, de perguntas que não se calam com respostas previamente esperadas, mas que usinam a energia, transformando em potência aquilo que se faz represado pelos paradigmas, pelos experimentos, pelos métodos, pelas análises. E, assim, as pesquisas que temos desenvolvido com crianças e produção de imagem no campo da Educação e da Educação Matemática levantam-nos muitas questões. Entre elas, destacamos: o que podem pesquisas com crianças e produção de imagens ajudar-nos a pensar sobre a educação, sobre pesquisa em educação, sobre a educação matemática, sobre pesquisas em educação matemática com crianças pequenas? Como habitar espaços de pesquisas em Educação e Educação matemática quando ocupamos caminhos 
impulsionados pelo acaso, pelo inesperado, pelos achados, pela experiência de sermos provocados pelas crianças, pelas imagens produzidas por elas, pelas leituras? O que pode uma pesquisa que parte da entrega de filmadoras, de câmeras fotográficas e ipads a crianças da educação infantil, para que, sem orientação prévia do adulto, produzam imagens (vídeos e fotografias) dentro do espaço da educação infantil? Qual o lugar da infância, da criança e da educação infantil no campo científico, especificamente no campo da educação, da educação matemática?

Assim acreditamos que a pesquisa apresentada traz uma discussão importante para a educação matemática: uma educação matemática atenta, que se distinga por uma atitude frente às múltiplas dimensões do aprender (GALLO, 2012), que se configura em um movimento de invenção recíproca e indissociável de si-matemática e do mundo. A pesquisa com crianças aproxima-nos de uma educação matemática que se abre à aventura ao desconhecido, de uma matemática inventiva, brincativa, sem função explicativa, descritiva, padronizativa. A discussão que trazemos não é um acaso, e sim uma escolha. Escolhemos trilhar caminhos que se aproximam mais da infância e das crianças para pensarmos a educação matemática, ainda que nesse percurso tenhamos encontrado outras coisas.

Nesse contexto, decidimos trazer para essa escrita parte do estudo Devir-criança da matemática: experiências educativas infantis imagéticas, desenvolvido junto ao programa de pós-graduação em Educação Matemática e ao Im@go: Laboratório da imagem, experiência e criação, o qual possibilitou encontros com a infância, com a matemática e com a educação. A pesquisa que dispara o estudo foi desenvolvida na educação infantil, no município de Vilhena, em Rondônia, com crianças de 04 a 05 anos, durante o ano letivo de 2012, no qual as crianças, sem orientação prévia, produziram o que chamamos de imagens e cenas lúdicas de experiências infantis.

O texto que segue, primeiramente, discute a pesquisa e sua relação com o conceito de experiência, como movimento de colocarmo-nos a prova, à criação, a invenções e a experimentações de sentidos, de sensações, de saberes. Segundamente, partimos das seguintes inquietações: o que a matemática, como forma, como identidade, colocando-se em devir, em devir-criança pode desdobrar? Invenção? Experimentação? Encontros? Esquecimento? Amizade? Ensaiamos, aqui, pensar, a partir do exercício do olhar das crianças, das produções imagéticas delas, a infância, a matemática e a educação com um olhar criança, de descoberta, de invenções, de criações, e, com isso, com as imagens infantis, pensar algumas travessias do universo infantil. 


\section{Pesquisa e experiência}

Tomemos a discussão sobre o conceito de experiência, situando-o na pesquisa. Para isso, poderíamos utilizar a metáfora do vidro para tratar da ciência moderna e sua relação com a experiência, pois "não é por acaso que o vidro é um material tão duro e tão liso, no qual nada se fixa. É também um material frio e sóbrio. As coisas de vidro não têm nenhuma aura. O vidro é inimigo no mistério" (BENJAMIN, 1994, p.117). Algo indica que foi dentro dessa moldura de vidro que a ciência moderna postulou seus ideais de verdade que distanciaram o homem da produção de conhecimento e, em troca, decorou a ciência das palavras rigor, neutralidade, objetividade e tantas outras. Tantas, tantas outras que apagaram os traços humanos da ciência atacando o mais íntimo de nossa existência: a experiência sensível.

Um dos primeiros passos para refletirmos sobre o conceito de experiência é distanciar nossos olhares da definição empírica de experiência, que remete à ideia de experimento. Ela teria, dessa maneira, a função de comprovar aspectos da realidade por meio de testes experimentais, mais segura, portanto, que a experiência como era tradicionalmente entendida. Isso se deve ao advento da ciência moderna, que instaurou um novo paradigma, o qual, entre outras coisas, possibilitou a fusão entre experiência, conhecimento e ciência, fato que acabou por reduzir a experiência ao experimento (MEINERZ, 2008).

Percorrendo, dessa maneira, a história da Filosofia, vemos que a experiência, antes desse marcante episódio, possuía um lugar específico. Para Aristóteles, por exemplo, a experiência estava relacionada à apreensão do singular, enquanto a ciência preocupava-se com o universal. Nesse sentido, experiência configurava-se enquanto confirmação da realidade por meio da verificação sensível. Já no pensamento medieval, o que impera é a dicotomia entre ciência e experiência, e, apesar disso, a experiência vai ganhando outros contornos: "o homem medievo conhece o mal por experiência, mas só pode conhecer o bem por ciência” (MEINERZ, 2008, p. 22). Na mesma direção, Descartes, citado por Agamben (2005, p. 26), diz que a experiência sensível assemelha-se a "um demônio cuja única função é a de enganar nossos sentidos", contribuindo para a criação de falsas versões da realidade.

Nesse momento, a experiência começa a aproximar-se da produção do conhecimento, mas não a experiência sensível, desprezada por Descartes, e, sim, a experiência como experimento, que se aproxima da verificação, da interpretação, e, por assim ser, da razão em detrimento dos sentidos. Desse modo, a experiência passa a ocupar um lugar fora do homem. A ciência moderna começa a utilizar a experiência como meio, como método de comprovação de hipóteses sobre os fenômenos, primeiramente, naturais, visto que no pensamento 
predominante, “[...] a experiência somente fornece proposições contingentes, as verdades eternas só são alcançadas por meio da razão" (MEINERZ, 2008, p. 23). Nessa perspectiva, $o$ que é, pois, experiência?

Larrosa (2002, p. 21) apresenta-se para ajudar-nos, dizendo que a experiência "é o que nos passa, o que nos acontece, o que nos toca. Não o que se passa, não o que acontece, ou o que toca". Ou seja, no nosso contato com a realidade, aquilo que nos forma, que nos transforma, que nos de-forma enquanto sujeitos; o que, pela nossa percepção, produz sentidos, que nos tira do esperado, do comum, do previsto, é a experiência que Benjamin (1994, p. 16) também anuncia,

[...] a força da estrada do campo é uma se alguém anda por ela, outra se a sobrevoa de aeroplano. [...] Quem voa vê apenas como a estrada se insinua através da paisagem, e, para ele, ela se desenrola segundo as mesmas leis que o terreno em torno. Somente quem anda pela estrada experimenta algo de seu domínio e de como, [...] ela faz sair, a seu comando, a cada uma de suas voltas, distâncias, belvederes, clareiras, perspectivas, assim como o chamado do comandante faz sair os soldados de uma fila.

Desse modo, é preciso que o sujeito seja sensível, esteja aberto ao mundo, que mantenha uma atitude de passividade para que, assim, os acontecimentos toquem-no. Lembrando que passividade, aqui, transcende a oposição entre passivo e ativo; de acordo com Larrosa (2002, p. 26) "definir o sujeito da experiência como sujeito passional não significa pensá-lo como sujeito incapaz de conhecimento, de compromisso ou ação. [...] O sujeito passional tem também sua própria força [...]”. Nas palavras do supracitado autor, o sujeito da experiência configura-se como um território de passagem, e, por isso, ele não é

[...] um sujeito que permanece sempre em pé, ereto, erguido e seguro de si mesmo; [...] o sujeito da experiência é [...] um sujeito sofredor, padecente, receptivo, aceitante, interpelado, submetido. [...] Somente o sujeito da experiência está, portanto, aberto à sua própria transformação (LARROSA, 2002, p. 25-26).

Nesse processo, a calma, o tempo, o ócio, o estar despreocupado, o desligar-se dos discursos, das análises e das previsões fazem-se necessários, pois, conforme afirma Benjamin (1994, p. 294), “o tédio é o passado do sonho que choca os ovos da experiência. O menor sussurro nas folhagens o assusta". É como se tivéssemos de voltar à infância para novamente espantarmo-nos com as coisas, permitindo que, antes de falarmos algo sobre os acontecimentos, que eles digam algo a nós, ou sobre nós. Evocando outras vozes, teríamos que atingir o espírito criança de Nietzsche (2008, p. 39), aquele que é "[...] criador livre e inocente, sem porquês nem para quês, isto é, desinteressado", ou o estar quando infante, de Manoel de Barros (2010, p. 113), que permite “[...] ir às origens de uma coisa ou de um ser", para livrarmo-nos das amarras da razão. Talvez, assim, seja possível lançarmo-nos ao 
movimento da vida. Portanto, para que a experiência aconteça, é preciso deixar-se conduzir, uma vez que "o sujeito da experiência é um sujeito 'ex-posto"” (LARROSA, 2002, p. 24-25), que não está preocupado em se pôr, em se opor, em se impor, ou em propor; ele simplesmente se põe a caminhar.

Nesse ponto intensifica-se a angústia de Benjamin, pois, ao tratar da experiência, ele percebe a dificuldade do homem em admitir-se enquanto sujeito da experiência. As brechas para a afetação pela vida acabam, dessa maneira, tornando-se cada vez mais raras. Vemos, assim, no texto $O$ narrador, escrito por Benjamin, que, ao passo que as pessoas buscam a informação, a narrativa fundamental para o compartilhar das experiências do viajante, do comerciante e do ancião, deixa de tocar os sujeitos.

[A] cada manhã recebemos notícias de todo o mundo. E, no entanto, somos pobres em histórias surpreendentes. A razão é que os fatos já nos chegam acompanhados de explicações. Em outras palavras: quase nada do que acontece está a serviço da narrativa, e quase tudo está a serviço da informação (BENJAMIN, 1994, p. 203).

Segundo Benjamin (1994, p. 204), a autoridade da narrativa está, principalmente, na não explicação dos fatos; isso lhe conserva a tradição, pois a narrativa "não se entrega. Ela conserva suas forças e depois de muito tempo ainda é capaz de se desenvolver", diferentemente da informação, que "aspira verificação imediata" e que nada tem a ver com a experiência do sujeito. Ela está fora do sujeito, pois acontece fora dele; apresenta-se quase como uma antiexperiência. Nas palavras de Larrosa (2002, p.22),

[...] a informação não faz outra coisa que cancelar nossas possibilidades de experiência. O sujeito da informação sabe de muitas coisas, passa seu tempo buscando informação, [...], porém, com essa obsessão pela informação e pelo saber (mas saber não no sentido de "sabedoria", mas no sentido de estar "bem informado"), o que consegue é que nada lhe aconteça.

Além da evidência no texto $O$ narrador de que a informação foi decisiva para o declínio da arte de narrar, por causar a expropriação da experiência no sujeito, é pontuado que um dos primeiros indícios da morte da narrativa deu-se pelo desenvolvimento do romance, já que ele transfere os momentos coletivos de troca de experiências para o sujeito-leitor isolado, devorando histórias muitas vezes sem relação alguma com a sua vida.

Para Benjamin (1994, p. 214),

[...] o romance não é significativo por descrever pedagogicamente um destino alheio, mas porque esse destino alheio, graças à chama que o consome, pode dar-nos o calor que não podemos encontrar em nosso próprio destino. $\mathrm{O}$ que seduz o leitor no romance é a esperança de aquecer sua vida gelada com a morte descrita no livro.

Nessa bela crítica literária, o autor traz uma reflexão sobre a vida e como temos dela nos distanciado na modernidade. Já não somos capazes de aceitar a realidade como ela é. Isso fica evidente quando percebemos que a morte alheia que nos chama à leitura de romances 
serve como um disfarce para a questão de nossa própria existência, já que "hoje, a morte é cada vez mais expulsa do universo dos vivos" (BENJAMIN, 1994, p. 207).

E, ainda que a morte tenha permanecido nas histórias, seu rosto é transformado, não servindo mais de substância para a criação dos narradores, sendo que "essa transformação é a mesma que reduziu a comunicabilidade da experiência à medida que a arte de narrar se extinguia" (BENJAMIN, 1994, p. 207). Reportamo-nos à questão da morte, pois Benjamin utiliza-a para mostrar quando a experiência alcança a instância do transmissível, dizendo que é na hora da morte que o saber, a sabedoria e a existência vivida do homem apresentam-se mais claramente.

Há, ainda, outras figuras que tentam ilustrar o narrador e que nos ajudam a entender essa substância que nutre suas histórias, são elas: o marinheiro comerciante e o camponês sedentário. Ambas as personagens são criadas a partir da experiência que passa de pessoa a pessoa. E essa experiência que se encontra no entre das coisas é a fonte maior dos narradores. Aliás, tanto quem viaja tem muito que contar quanto um homem que nunca saiu de seu país e que conhece suas histórias e tradições. Benjamin (1994, p. 199) diz que "no sistema corporativo associava-se o saber das terras distantes, trazido para casa pelos migrantes, com o saber do passado, recolhido pelo trabalhador sedentário”. E, por que não conseguimos, até hoje, juntar o saber do trabalhador sedentário, que pode ser comparado ao saber cientificamente produzido pela academia, com o saber trazido pelos migrantes ou marinheiros comerciantes, vulgo sujeitos de nossas pesquisas, que, sem as responsabilidades próprias do pesquisador, lançam-se à experiência?

Isso, para Benjamin (1994, p. 198), há muito já não é possível. Ele indica que "estamos privados da capacidade de intercambiar experiências e uma das causas desse fenômeno é óbvia: as ações da experiência estão em baixa, e tudo indica que continuarão caindo até que seu valor desapareça de todo". Isso porque, além da arte de narrar ter desaparecido, o lado épico da verdade também está em vias de extinção. Assim “o saber que vinha de longe - do longe espacial das terras estranhas, ou do longe temporal contido na tradição-, [que] dispunha de uma autoridade que era válida mesmo que não fosse controlável pela experiência" perdeu seu espaço. Tanto nas narrativas como na produção de conhecimento sobre o mundo.

O declínio da experiência também é discutido no texto Experiência e Pobreza, de Benjamin, no qual o autor traz uma reflexão sobre como a humanidade foi perdendo a capacidade de ter e transmitir experiências. Para apresentar tais questões, ele se vale da literatura, da arte, e das narrativas. Estas, por sua vez, mostram-se como disparadores da 
problemática do culto ao homem moderno, fato que acabou desumanizando o próprio homem. Além disso, encontramos elementos nesse pequeno texto para uma discussão acerca da cultura e do desenvolvimento da técnica. Vale ressaltar que o texto é carregado de certo pessimismo do autor em relação à situação do homem frente aos acontecimentos do mundo e aos encaminhamentos da sociedade. Contudo, neste momento, ater-nos-emos somente ao declínio da experiência.

O autor identifica que, após a destruição causada pela guerra na Alemanha, os sujeitos tornaram-se mais pobres em experiências compartilháveis, tanto que os sobreviventes, ao invés de terem histórias para contar aos outros, voltaram silenciados.

[...] nunca houve experiências mais radicalmente desmoralizantes que a experiência estratégica pela guerra de trincheiras, a experiência econômica pela inflação, a experiência do corpo pela fome, a experiência moral pelos governantes (BENJAMIN, 1994, p. 115).

Nesse cenário, Benjamin (1994, p. 115) aponta que o homem nada mais é do que um “frágil e minúsculo corpo humano" indefeso, que já não se reconhece na tradição de seu povo, nem na paisagem que o rodeia, assim "é preferível confessar que a pobreza de experiência não é mais privada, mas de toda a humanidade." Na era moderna, portanto, o homem almeja libertar-se de toda e qualquer experiência.

Parece que o objetivo da vida não passa de um remoto ponto de fuga, pois “[...] surge uma existência que se basta a si mesma, em cada episódio, do modo mais simples e mais cômodo [...]" (BENJAMIN, 1994, p. 119). Vemos isso na figura do homem moderno, que devora tudo - informações, produtos, modos de ser e estar no mundo - e fica saciado.

Segundo Silva (2011, p. 30), "aliado à velocidade em que se sucedem os acontecimentos, o nosso insaciável interesse pelo novo contribui para que tais experiências não nos deixem marcas; assim, elas não se traduzem em experiência”. É como Vale (2011, p. 8) afirma em seu texto Cultura de vidro, "Estamos pobres em experiências, pois já não nos preocupamos em passar adiante tudo àquilo que nos torna humanos que, certamente, não estão ligados a títulos, bens materiais...”.

Giorgio Agamben (2005) é outro autor que se apresenta para complementar tais discussões. Além de ser leitor de Benjamin, ele também trata do conceito de experiência, apesar de sua preocupação maior ser a questão do conhecimento. $\mathrm{O}$ fato é que, com o surgimento da ciência moderna, a experiência e o conhecimento passaram a ser sinônimos, de modo que a experiência passa a ser o caminho, o método para chegar-se ao conhecimento. E é por esse motivo que Agamben tece uma discussão sobre a destruição da experiência. 
Passando por questões como a expropriação da experiência por conta da informação, Agamben (2005, p. 21-22) aprofunda essa discussão, dizendo:

[...] nós hoje sabemos que, para a destruição da experiência, uma catástrofe não é de modo algum necessária, e que a pacífica existência cotidiana em uma grande cidade é, para esse fim, perfeitamente suficiente.

$[\ldots]$

O homem moderno volta a casa à noitinha extenuado por uma mixórdia, de eventos - divertidos ou maçantes, banais ou insólitos agradáveis ou atrozes - entretanto nenhum deles se tornou experiência.

Isso se deve ao fato de o cotidiano ter se tornado opressor por sua ligação moderna com o extraordinário, antes "todo evento, por mais comum e insignificante, tornava-se a partícula de impureza em torno da qual a experiência adensa, como uma pérola, a própria autoridade" (AGAMBEN, 2005, p. 22). Segundo o autor, a busca pelo novo, pela informação e pelo extraordinário suspendem nossas possibilidades de ter experiências; possibilidades que, de alguma forma, estariam relacionadas à capacidade de subtrair a novidade das coisas, neutralizar seu poder de choque. Não que atualmente não existam mais experiências, porém “estas se efetuam fora do homem” (AGAMBEN, 2005, p. 23).

Apesar dessas constatações, para Agamben (2005, p. 26) a captura da experiência pela ciência moderna, em seu projeto de alcançar a verdade, foi o fator determinante da expropriação da experiência do sujeito, pois a "[...] a experiência é incompatível com a certeza, e uma experiência que se torna calculável e certa perde imediatamente a sua autoridade". Desse modo, a experiência passa para a instância do traduzível, não mais para a esfera do transmissível, como Benjamin (1994) traz, e, sim, efetuando-se enquanto experimento na tentativa de quantificar com exatidão nossas impressões sensíveis.

O problema central para Agamben (2005, p. 27), portanto, finda-se nessa noção de que o conhecimento acontece a partir de experiências/experimentos, de capturas da realidade, de busca pela certeza, já que, para ele, o saber humano dá-se "somente através de e após um sofrimento [que seria a própria experiência em seu sentido tradicional], que exclui toda a possibilidade de prever, ou seja, de conhecer com certeza coisa alguma".

Parece que aproximar a pesquisa à experiência abre espaço para percebermos esse movimento da infância, as incertezas, que permite um caminhar cheio de descobertas e exposição. No entanto, para que consigamos olhar e afetarmo-nos por esses acontecimentos, é necessário um deslocamento, é necessário que também saiamos dos nossos lugares seguros e coloquemo-nos a caminhar. Deixar-se levar pela estrada, que é sensível aos acontecimentos, que se abre a olhar o mundo assim como ele se apresenta, e que, por tudo isso, assemelha-se a uma criança vendo o mundo pela primeira vez, não é de modo algum confortável. Para que 
possamos libertar o nosso olhar, precisamos fazer um esforço. Nas palavras de Masschelein (2008), "para sair pelo mundo é suficiente fazer um esforço", nesse sentido, para colocarmonos a caminho pela estrada, para realizarmos uma pesquisa com crianças, para olharmos as imagens que as crianças nos apresentam, precisamos do mesmo esforço. E esse esforço é quase uma imposição que se exerce em nós. Ela pressiona a olhar e exige, por necessidade, atenção, postura, atitude e posicionamento crítico.

Quando abandonamos um pouco as verdades absolutas, as coisas certas, as linhas retas, e tomamos como ponto de partida, ou modo de vida, a experiência de olhar o mundo como se fosse a primeira vez, como as crianças, e damos lugar à experiência que corta, transforma, transborda os limites, o que podemos encontrar? Quais são nossos achados? Que achados as crianças apresentam a nós nesse percurso e qual a importância desses achados para pensar-se a infância, a criança e a matemática na escola?

\section{Devir-criança da matemática: inquietações e experimentações}

As filmagens produzidas pelas crianças fazem-nos pensar que elas, as crianças, têm uma relação infantil com as coisas, com o mundo que as cerca. Quando falamos de infantil, não nos referimos a uma relação inferior, uma relação de quem não sabe, a uma relação que precisa ser tutelada, muito pelo contrário, referimo-nos a uma relação de diferença, de saberes outros.

As produções imagéticas apresentam a nós crianças que pensam e experimentam, pensam e experimentam muito o mundo, as coisas, os seres pequenos e desimportantes. É esse pensar e experimentar infantil que as crianças, o devir-criança fazem-nos pensar: o que a matemática, como forma, como identidade, colocando-se em devir, em devir-criança pode desdobrar? Ora, a organização molar da matemática, sua historicidade, sua estrutura, "sua segmentaridade dura não impede todo um mundo de microperceptos inconscientes, de afetos inconscientes, de segmentações finas, que não captam ou não sentem as mesmas coisas, que se distribuem de outro modo, que operam de outro modo", como afirmam Deleuze e Guattari (1996, p. 83). É a matemática molecular, um devir-criança da matemática operando fora dos reis e das regências, das regras e convenções, das normas e dos acordos. Ele não se define pelo certo e pelo errado, pelas certezas dadas e definidas, pelas formas e estruturas, pelas identidades, pela reprodução, mas rompe com a ordem estabelecida, com os dogmas, dificulta o reconhecimento, adota o esquecimento para se que entre no movimento de nascimentos sem origem, ou seja, produz nas dobras desdobramentos de invenção, pura invenção. 
Gente $^{2}$ já sei vamos fazer de grupo em grupo.

Ah, não! Vamos fazer assim desse jeito. Vamos fazer uma roda, uma roda, roda.

Não!

Assim, trenzinho!

Eu dirigia.

Hein, eu queria dirigi.

Vamo.

Briimmmm, aummmm,

Hein, o trem é aqui.

Hein, quem vai pra estação?

Quem vai descer em Cerejeira?

Quem vai descer em Cacoal?

Eu não!

Ô João Vitor, você vai descer em

Cacoal?

Quem vai descer em Cuiabá?
É assim os vago do trem! É Assim!

Você vai descer aonde?

Em lugar nenhum.

Eu não vou descer.

Você vai pra que cidade?

Pra lugar nenhum.

Não pode dentro do ônibus, você vai morrer, o ônibus tá andando.

Entra em outro trem!

Eu já cheguei de volta.

Vai que o ônibus vai andar.

Eu vou parar lá em Ji-Paraná.

Eu vou pra Porto Velho.

Então vai com ela porque ela vai pra

Porto Velho.

Eu vou dirigindo.

Você vai dirigindo pra levar o trem pra

Porto Velho.

Pare o ônibus! Pare o ônibus!

(Pré II, 2012, 129)

As produções imagéticas das crianças dão pistas para pensar no movimento de um devir-criança da matemática. A primeira delas pode ser expressa como uma relação "de experimentação mais próxima com o meio molecular”, como aponta Kastrup (2000, p. 378). As imagens produzidas apresentam crianças que experimentam, experimentam-se e deixam-se experimentar, exploram o mundo, os seres as coisas. Nesse sentido Deleuze (1997, p. 83) afirma que "A criança não para de dizer o que faz ou tenta fazer: explora os meios, por trajetos dinâmicos, e traça o mapa correspondente".

Um devir-criança da matemática acontece na experiência, na infância do mundo, na infância das coisas, pois é na infância que experienciamos a vida, o mundo e experimentamos distanciados das amarras da razão, afastados dos aprisionamentos, das certezas. Nasce na abertura, no desconhecido, na imprevisibilidade, na incerteza, no descontrole, foge dos modelos, dos dispositivos que querem normatizar e regulamentar sua existência. Poderia dizer mais, é povoado de desejos, das necessidades da imaginação e da paixão. Agamben (2005, p. 25) afirma “[...] a experiência não é mais que uma vassoura desmantelada, um proceder tateante como o de quem perambulasse à noite na esperança de atinar com a estrada certa”.

\footnotetext{
${ }^{2}$ As falas das crianças foram retiradas das filmagens produzidas por elas durante o período que estivemos na instituição de educação infantil, que corresponde a 08 meses, em 2012. Optamos por referenciá-las de acordo com a maneira que os documentos imagéticos foram arquivados. Assim o número ordinal refere-se à ordem ao dia (primeiro dia, segundo dia, e assim sucessivamente), o número cardinal em seguida refere-se ao número de filmagens no dia.
} 
A conversa entre três meninas chama a atenção quando uma delas pergunta para as demais: “quanto é zero mais zero?" Ela faz o sinal do número dois no ar com o dedo, bastante séria. As colegas demoram cerca de alguns segundos para responder, por isso ela não as espera e responde: “um zero mais outro zero é dois zeros" (PRÉ-ESCOLA II, 2012, 16 15). Poderíamos dizer, inspirados em Manoel de Barros (2013, p. 441), que as crianças arrombam as normas, as regras, as técnicas, por que não, a gramática matemática, "ao falarem absurdez, abortam o bom senso". Elas não sabem, por exemplo, que o zero é um elemento neutro na adição. Então as crianças inventam e mudam a função do zero, mudam a função zero das coisas, porque elas povoam o vazio, e, com isso, o zero delira. O devir-criança da matemática compõe-se com os restos da matemática escolar, e não em oposição a ela, distanciando-se da matemática de tanque que está estagnada, estanque e pode até mofar.

A segunda pista diz respeito a um movimento temporal, que indica um tempo ou tempos distantes do tempo numerado, sucessivo, orientado. Esse tempo, que povoa o devircriança da matemática, é o tempo kaiônico ${ }^{3}$, Kairós e Aiôn juntos, movendo-se pelas situações, atentos às ocasiões. Esse tempo não se define por uma linha contínua de movimentos sucessivos, mas acontece num movimento circular de repouso, lentidão e velocidades repleto de intensidades. É um tempo infantil, que, enquanto Chronos segue os números, Kaiôn ${ }^{4}$ brinca com eles. É, ainda, um acaso, uma oportunidade, um acontecimento, lampejoso como um raio que prenuncia algo de inesperado, de imprevisível. Ele não pode ser medido, nem especificado, muito menos definido, não reflete o passado, nem antecipa o futuro. É um tempo indefinido, é o melhor no instante presente, é a própria suspensão do tempo. Não é regular, nem homogêneo, nem pertence ao mundo dos relógios, das ampulhetas, ou a qualquer outro instrumento de medida tempo. É multiplicidade em movimento intenso, uma força infantil, desigual, sublime ocasião, que só aparece desaparecendo.

Enquanto Kairós "faz aparecer a solução como algo brusco, brutal e revolucionário" (DELEUZE, 1988, p. 182), Aiôn, tempo indefinido do acontecimento, só “conhece velocidades e ao mesmo tempo não para de dividir o que acontece num já-aí e um ainda-nãoaí, um tarde-de-mais e um cedo-demais simultâneos, um algo que ao mesmo tempo vai se passar e acaba de se passar" (DELEUZE; GUATTARI, 1997, p.51). Juntos, esse tempo Kaiônico movimenta-se em todos os sentidos, ao mesmo tempo, sem nunca se deterem, sempre se desviando do presente. Vai de trem, vai de ônibus, para Cacoal, para Cerejeira, Porto Velho, Ji-Paraná... Ao mesmo tempo, em todos os tempos, para todos os lugares, de

\footnotetext{
${ }^{3}$ Combinação das palavras Kairós e Aiôn.

${ }^{4}$ Combinação das palavras Kairós e Aiôn.
} 
todas as maneiras, no mesmo instante, no mesmo lance, em todas as direções, em todos os sentidos. Um tempo penetrando o outro, coexistindo com ele em todas as temporalidades. Misturados, embolados, rizomados. Como isso é possível? Como é possível movimentar-se sem sair do lugar, sem temporalizar as idas, vindas e voltas? Como é possível habitar sem fixar? Um devir-criança da matemática é uma criança crianceira; criançando ela reina em Kaiôn, tempo da criação, da invenção.

Então, as produções imagéticas das crianças levam a pensar em tempos, outros tempos. Tempos, que sendo outros, não estão vinculados à linearidade, mensurabilidade, ao tempo cronológico, no qual estão presentes nas práticas educativas, no currículo, e em todas as ideias que norteiam o que as crianças devem saber e aprender em qual faixa etária, em qual estágio da vida. As imagens produzidas pelas crianças, imagens trêmulas, embaçadas, rápidas, curtas, desfocadas, paradas, em movimento convidam-nos a pensar no tempo kaiônico, no tempo oportuno, acontecimento, experiência. Ou seja, o que as crianças devem aprender e saber dentro de um tempo cronológico está lá estabelecido, previsto e sendo cumprido. Entretanto as crianças atravessam esse tempo, esse conteúdo, esses saberes, essas práticas e escapam às modulações ou aos clichês presentes nos ditos e não ditos e nos modos de sentilas, de percebê-las, de pensá-las. Por isso, o tempo de um devir-criança da matemática é um tempo fora do tempo histórico, um tempo sem marcação, sem começo, nem fím, nem linearidade. É tempo do imprevisto, do ainda não pensado, do incontrolável, do incalculável.

As imagens produzidas pelas crianças apresentam outra pista para pensar o movimento de um devir-criança da matemática: a profanação da ritualização. Nesse caso, o jogo é um indício de profanação daquilo que com o tempo sacraliza-se, adquire forma, permanência e generalidade. Para Agamben (2005, p. 89), "Enquanto o rito transforma eventos em estruturas, o jogo transforma estruturas em evento." As crianças celebram os ritos, manipulam objetos e palavras sagradas, porém esquecem, ou mesmo desconhecem, o sentido e o escopo, como ainda aponta Agamben. É o jogo, é a brincadeira que nos tira da esfera do sagrado, da ritualização e devolve ao livre uso o que está consagrado. Nesse movimento, o uso dos objetos, dos espaços, dos lugares, do mundo, dos seres, das coisas, além de livre é negligente, distraído, desabusado e desautorizado.

Cabe pensar, aqui, nos movimentos do jogo, da brincadeira, movimentos esses que lembram o mover-se de um dançarino de pés leves, envolvente, sedutor, encantador que cria e inventa, sempre inesperadamente, um novo jogo de sedução. Envolvidos pela dança, pela mobilidade, pelo deslocamento põe à prova o mundo, os seres as coisas, desarmando-os de toda fixidez, pondo-os a dançar guiados por um caminho cujo fim é desconhecido. Um devir- 
criança da matemática é acaso que seduz e é seduzido, por isso quer apenas dançar com os pés do acaso, como nos dirá Zaratustra (NIETZSCHE, 2011, p. 232) "Deixai vir a mim o acaso; ele é inocente como uma criança". É nesse jogo, nessa brincadeira dançante que esquecemos a prisão, que fazemos tremer tudo quanto é fixo. Um devir-criança da matemática joga, brinca, profana, dança como se flutuasse ou pairasse no ar, ele é livre das amarras porque seus pés são leves. Ele coloca para dançar o corpo e, no mesmo movimento, por contaminação, todo pensamento aprisionado por regras embrutecidas.

As produções imagéticas apresentam crianças que profanam o tempo todo, todo o tempo. Elas profanam o tempo escolar, tempo tipicamente cronológico, sucessivo, introduzindo o tempo kaiônico, intensivo, instantâneo e ocasional. Profanam o tempo a ser utilizado, o que deve ser feito, quem elas devem ser (alunas e não crianças, mãe, filha, bicho...), os objetos, os modelos dados, o currículo escolar, os lugares habitados, profanam... Então, parece que um devir-criança da matemática também profana, e, assim, não segue modelos, não segue ordenação, nem regras previamente estabelecidas, foge dos modelos ideológicos prontos, do imobilismo e da estagnação; é uma criança livre de amarras. Não espera para ser sentido e experienciado.

Oh! O número da minha casa, da minha casa, se vocês querer ir na minha casa, na minha casa, o número da minha casa é seis, cinco, dois, seis. Daí vocês já vira para minha casa, daí minha mãe tá lá pra receber vocês (PRÉ I, 2012, 10 1).

As produções imagéticas das crianças apresentam situações em que um devir-criança da matemática profanadora acontece. Parece-nos que, no enredo acima, o número é usado como orientador, direcionador, localizador. Ele aparece para identificar, localizar a casa, indicar, dar rumo ao caminho, ele aparece para disparar, experienciar a potência do encontro, e esse encontro é provisório, passa como um lampejo, seja para a própria criança, seja para as outras crianças que são afetadas pelo encontro.

Aqui as crianças profanam o currículo escolar, o conteúdo curricular limitado aos números (de zero a dez) como representação simbólica que são submetidas, elas usam desabusadamente e desautorizadamente os saberes. As crianças fogem do currículo que cria ordem reguladora de suas subjetividades, fogem das representações, não porque elas as conhecem, mas porque as ignoram. A representação está no lugar de, no lugar da coisa, e revela uma única verdade, dita palavras de ordem, e toda palavra de ordem aprisiona, ou seja, a representação homogeneíza o pensamento, dita condutas e saberes; cria um perfil, uma identidade, um papel, e isso faz reproduzir um modelo. Um devir-criança da matemática não é representativo, ele não habita o campo da representação, mas entra no campo das sensações, 
por isso opera com o pensamento de modo que faz gerar essa coisa mais lúdica, fantasiosa, imaginativa, inventiva, sensitiva.

Podemos pensar, aqui, na ideia de algo que é sagrado (currículo e aula) que pode ser profanado, quando, por exemplo, as crianças durante a aula brincam com um jogo de sequência e deixam de lado a aula, ou quando, durante a explicação de uma atividade, uma das crianças orienta as demais a chegar à sua casa, ou, ainda, no momento do lanche, hora de ficarem em silêncio, as crianças explicitam suas conjecturas. Nessas ocasiões, elas tornam o jogo divino no momento de aprendizagem pela experiência. Com isso rompem com o embrutecimento (RANCIÈRE, 2012) das formas de conhecimento que atuam na vida, rompem com a rigidez das formas de conhecimento que atuam no âmbito escolar.

Às vezes, as conversas das crianças parecem, para nós, despropósitos, mas para elas não o são. Parece-nos que um devir-criança da matemática movimenta-se na aprendizagem pela experiência, como diz Larrosa (2002, p. 28), "na prova e pela prova, com toda a incerteza que isso implica", por isso ela não tem limites e nem sequência para acontecer, foge dos artefatos técnicos, da inflação de conhecimentos objetivos, não é e nem tem verdades absolutas; pelo contrário, ela obedece à desordem. Leite (2011, p. 161) diz que a experiência “[...] não prescreve verdades, e nem pode ser prescrita por outras verdades que a antecederam, ela sempre cria espaços de incertezas, embora também tenha achados".

Eu sei, eu sei contar número em inglês, você não sabe falar assim, uon, thil, three, for, vaive, six, eith, nei, teem, isto que é inglês. Eu também sei.

Então fala.

Como você falou mesmo? Assim, como que vocêfalou mesmo?

Uon, thil, three, for, vaive, ix, seven, eith, nai, teem.

Isso aqui também é inglês uai, thau, teem, o que mais? (PRÉ I, 2012, $4^{\circ} 18$ ).

O devir-criança da matemática não se prende ao acúmulo de informação, não está preso ao âmbito estritamente objetivo da realidade, não está preso às explicações concretas, objetivas, mas, sim, é movido pela vontade, pelo desejo, pelo prazer de brincar, de adivinhar, de divinare. Como diz Barros (2013, p. 316), "quem acumula muita informação perde o condão de adivinhar: divinare". Por isso não é informação, nem acumulação progressiva de verdades, ou, como afirma Larrosa (2002, p. 21), "a informação é quase que uma antiexperiência", ela é quase o contrário da experiência”. Ou seja, a matemática escolar vem carregada de informação e dificulta as possibilidades de as crianças experienciarem, movimentarem em devires. Depois de uma aula em que, por exemplo, um número é mostrado, informado, em que as crianças contam, pintam a quantidade numérica representativa, é possível dizer, de acordo com Larrosa (2002, p. 22), que as crianças sabem 
um número, uma representação numérica que não sabiam antes, que elas têm mais informação sobre o ou do número, mas "ao mesmo tempo podemos dizer que nada as tocou, nada lhes aconteceu, que com tudo o que elas aprenderam nada lhes sucedeu ou lhes aconteceu". Assim o devir-criança da matemática não perde a varinha mágica que transforma o real, não perde o mistério, não perde o segredo do que não se explica por meio da informação, da notícia, do dado objetivo.

O corpo é o lugar onde a criança conhece a si e os outros, ao mesmo tempo em que inventa a si e outros. Ela explora a sensualidade e a intimidade corpórea dos seres, tocando-os e deixando ser tocada. Conforme Bachelard (1991, p.20), é possível afirmar que o corpo é dotado "do ato de nos tocar. Ele nos toca assim como o tocamos, dura ou suavemente". Portanto, pensar resulta do encontro de um verdadeiro corpo a corpo, no qual o toque, o contato é dotado de uma alegria, de devaneios, de delírios inventivos e inaugurais, que dão vida aos diferentes modos de ser e de existir.

A comunhão, as núpcias entre os corpos perturbam nossos sentidos e faz gerar uma percepção mais íntima do mundo, fazendo-nos ater aos detalhes que nos cercam: cores, sabores, odores, olhares, toques, texturas, sons. Não é somente o tato que sente, os olhos que veem, o ouvido que ouve, a boca que sente paladar. Mas todos os sentidos confluindo para pensarmos; pensando, tornamo-nos outros, tornamo-nos mundo. Pautados em Bachelard (1998, p. 49) diríamos que "as coisas não são o que são, são o que se tornam. Tornam-se, em nosso devaneio", em nossos intermináveis delírios. Pensar a água é escoar-se, é dissolver-se, é morrer. Pensar o fogo é sentir-se, tornar-se chama, impulso, brilho. Pensar o mundo é tornarse chão, céu, sol, folha, a filha da formiga, é entrar na trilha do macaco, e, quem sabe, ser conduzido com ele a expedições indefinidas, labirínticas, sem saber muito bem aonde vai chegar, ou se vai chegar.

Dessa maneira, as imagens infantis apresentam a nós um devir-criança da matemática que escapa às modulações, às respostas certas, às verdades absolutas. Escapa aos modos reguladores de ser e de pensar-se, escapa às modulações de tempo, de espaços e de corpos. Elas vivem e convivem com a matemática presente no currículo, no tempo organizado, mas os ignoram, às vezes parece que nem os percebem, às vezes fazem até pouco caso desse currículo pré-estabelecido, desse tempo organizado, das atividades programadas. Elas, as crianças, organizam-se entre si, em reuniões, em assembleias, em concílios, para confabularem a vida, os seres, as coisas, o mundo. Entre iguais elas agem sem controle do adulto, sem tomar emprestado as ideias e as ações do adulto. Nessa relação entre iguais, elas pensam, produzem, criam, inventam, experimentam o mundo. Elas produzem novas palavras, 
novos pensamentos, mobilizam e provocam mudanças em si mesmas e nos outros, é o encontro entre pensamentos, com o pensamento da outra, com outro pensamento. Esses encontros entre crianças apresentam-nos uma explosão da potência do pensamento infantil.

As crianças são atravessadas pelo devir-criança da matemática que circula na vida, no mundo, na escola e lidam de outra maneira com ela, por estarem em um eterno movimento de travessias entre fronteiras. O movimento da experiência primeira, da experiência de fonte, da imaginação, da criação, da invenção. São atravessadas pela incompletude do mundo, pelos saberes primeiros, até mesmo pelos não saberes, pelas descobertas, pelos encontros, pelos achados, pelos acontecimentos. Entram em um tempo, em um espaço, em corpos, onde as horas correm como faíscas e a eternidade é como um verdadeiro presente.

As produções imagéticas das crianças, tão ricas em detalhes e sentidos, nos revelam que mais do que conteúdos de matemática, que dizem respeito ao conhecimento de número e sistema de numeração, de notação e de escrita numéricas, de grandezas e medidas, de espaço e forma, as narrativas e as imagens apontam para outras relações estabelecidas e modos distintos de criar conexões, principalmente como o pensamento das crianças parecem se organizar de um modo outro, não linear, não evolutivo, não compartimentado, não do geral para o específico, do simples para o complexo, como toda nossa sociedade é organizada, nosso currículo, nossa prática pedagógica e nossa escola.

\section{Um pós-escrito}

Mundos são criados, modos de apresentar-se para o outro são inventados, indagações tiram-nos dos lugares seguros e previstos, alguns ecos denunciam leituras e posicionamentos, enfim somos convidados a um exercício do olhar. Pesquisar com crianças, nesse contexto, convida-nos a ser tocados na pele, a ser tocados pelos acontecimentos, convida-nos, também, a uma reflexão acerca do olhar. De como olhamos e de como as crianças olham e olham a nós... De que modo e de onde se olha... Qual lente estamos usando para perceber os sujeitos/protagonistas de nossas pesquisas?

Tempos outros, de uma criança tomada por si mesma que pode mobilizar as potências de um devir-criança? Uma potência que permite pensar o convívio com as incertezas, sem se prender a modelos e a estratificações? Como seria pensar uma educação para criança a partir da criança? Uma educação em movimento, em outro tempo, em outros espaços, de saberes não fixados, nem organizados? As crianças lançam-se a descobrir, experienciar o mundo antes 
mesmo de nomeá-lo. Antes mesmo de alguém nomeá-lo a elas e por elas. As verdades produzidas pelas crianças consistem num contínuo e incessante desdobramento da diferença.

Ser transformado, ser afetado, ser contaminado é, sobretudo, “[...] colocar em dúvida as perspectivas, os lugares, as certezas”. Assim, pesquisar com crianças é um convite a caminhar e também um convite a educar o olhar; pesquisar com crianças é um convite à experiência e à dúvida de todas as certezas (LEITE, 2011, p. 128). Talvez, nossos encontros com a criança, com a infância pela criança, com a infância do mundo apontem-nos para uma educação matemática, uma educação na infância que nos possibilite pensar com as crianças uma educação, uma escola que fuja das imposições, dos modelos, que rompa com os rígidos protocolos de ações e impulsionem-nos a uma educação aberta ao acontecimento, a furar o planejado, a distanciar-se da repetição massificante. Uma educação que provoque, produza pensamento, pois nos parece ser esse o projeto também da matemática.

Essas crianças que estão na escola hoje, que resistem, que profanam, e que enfrentam a lógica pedagógica, trazem outros sentidos para a escola. Seus corpos historicizados, pensantes, brincantes apresentam em suas narrativas, nas interações e em todos os espaços escolares, outros modos de ser e estar no mundo, que ao negá-los a escola também os precariza. $\mathrm{O}$ estudo nos mostra que as crianças, seus saberes e suas profanações, introduzem na escola sua própria didática, sua forma particular de aprender, pelo corpo todo, outras formas e outros sentidos de escola, de políticas sociais, de mundo, de relação com o outro, de humanização. Elas, as crianças, constroem uma lógica, que, para além de pedagógica ou escolar, é uma forma potente e rigorosamente pensante, reflexiva, sentida, experienciada. Só a decifra quem, de fato, possa ter uma relação de intimidade com o saber das crianças, das infâncias, que questionam, que tensionam as estreitas e dolorosas armadilhas curriculares enformantes. Pensar uma educação matemática na infância, distanciada das engessadoras, que rompa com as amarras pedagógicas e históricas, que atravessam as camadas que incidem entre a pele e o osso dos corpos-vidas-crianças-infâncias, é um desafio que está estreitamente relacionado a outro comprometimento com educação e com as crianças.

Poderíamos pensar, então, em educação na infância sem conteúdo, sem forma, sem ordem, sem limites, sem aprisionamentos, uma fora da lei? Talvez, poderíamos dizer que há na infância, na criança, uma busca baseada em decisões não premeditadas, não préestabelecidas, em encontros não antecipados, provocados, suscitados e organizados. Lança-se a experienciar, experimentar o mundo produzindo regras, normas que duram infinitivamente quanto dura um instante. Para Bachelard (1988, p. 182), “o mundo é constituído pelo conjunto de nossas admirações. Admira primeiro, depois compreenderás”. Já Deleuze (1987, p. 95) 
afirma que "A inteligência vem sempre depois; ela é boa quando vem depois, só é boa quando vem depois".

Nesse sentido, retomamos, aqui, o poema epígrafe deste texto, Sempre compreendo o que faço depois que já fiz. O que sempre faço, nem seja uma aplicação de estudo. É sempre uma descoberta. Não é nada procurado. É achado mesmo (BARROS, 2010, p. 85), e perguntamo-nos: podem a Educação, a Educação Matemática, a Pesquisa em Educação e a Pesquisa em Educação matemática reinventar-se a partir do olhar infantil das aberturas, do novo, daquilo que inaugura?

\section{Referências}

AGAMBEN, Giorgio. Infância e história. Destruição da experiência e origem da história. Belo Horizonte: Editora UFMG, 2005.

BACHELARD, Gaston. A poética do devaneio. São Paulo: Martins Fontes, 1988.

BACHELARD, Gaston. A terra e os devaneios da vontade. São Paulo: Martins Fontes, 1991.

BACHELARD, Gaston A água e os sonhos. São Paulo: Martins Fontes, 1998.

BARROS, Manoel. Memórias Inventadas: as infâncias de Manoel de Barros. São Paulo: Editora Planeta do Brasil, 2010.

BARROS, Manoel. Poesia Completa. São Paulo: Leya, 2013.

BENJAMIN, Walter. Magia e técnica, arte e política. Obras Escolhidas I. São Paulo: Editora Brasiliense, 1994.

DELEUZE, Gilles. Diferença e Repetição. Rio de Janeiro: Graal, 1988.

DELEUZE, Gilles. Proust e os signos. Rio de Janeiro: Forense, 1987.

DELEUZE, Gilles. Crítica e clínica. São Paulo: Editora 34, 1997.

DELEUZE, Gilles; GUATTARI, Felix. Mil Platôs. Capitalismo e esquizofrenia. Vol 3. Rio de Janeiro: Editora 34, 1996.

DELEUZE, Gilles; GUATTARI, Felix. Mil Platôs. Capitalismo e esquizofrenia. Vol 4. São Paulo: Editora 34, 1997.

GAGNEBIN, Jeanne Marie. História e narração em Walter Benjamin. São Paulo: Perspectiva, 2011.

GALLO, Silvio. As múltiplas dimensões do aprender... Congresso de Educação Básica, Aprendizagem e Currículo. 2012. Disponível em:<

http://www.pmf.sc.gov.br/arquivos/arquivos/pdf/13_02_2012_10.54.50.a0ac3b8a140676ef8ae0dbf32e 662762.pdf>. Acesso em: 05 fev. 2015. 
KASTRUP, Virgínia. Devir-Criança e a Cognição Contemporânea. Psicologia: Reflexão e Crítica, inserir cidade, v. 13, n.3, p.373-382, jul - set, 2000.

LARROSA, JORGE. Notas sobre a experiência e o saber experiência. Revista Brasileira de Educação, Rio de Janeiro, n. 19, jan - abr, 2002.

LEITE, César Donizetti Pereira. Infância, Experiência e Tempo. São Paulo: Cultura Acadêmica, 2011.

MASSCHELEIN, J. E-ducando o olhar a necessidade de uma pedagogia pobre. Educação e Realidade, Porto Alegre, v. 33, n. 1, jan - jun, 2008.

MEINERZ, A. Concepção de experiência em Walter Banjamin. 2008. 81 f. Dissertação (Mestrado em Filosofia) - Instituto de Filosofia e Ciências Humanas. Programa de Pós-Graduação em Filosofia, Universidade Federal do Rio Grande do Sul, Porto Alegre, 2008.

NIETZSCHE, Friedrich Wilhelm. Assim falou Zaratustra. São Paulo: Companhia das Letras, 2011.

NIETZSCHE, Friedrich Wilhelm. As três metamorfoses: In: Assim falava Zaratustra: um livro para todos e para ninguém. Petrópolis, RJ: Vozes, 2008. p. 38-40

RANCIÈRE, Jacques. O espectador emancipado. São Paulo: Martins Fontes, 2012.

SILVA, Fernanda Lira da. Experiência audiovisual e infância: em busca do que escapa ao primeiro olhar. 2011. 111 f. Dissertação (Mestrado em Educação) - Instituto de Biociências, Universidade Estadual "Júlio Mesquita Filho", Rio Claro, 2011.

VALE, R. S. Cultura de vidro: uma crítica à modernidade a partir da visão benjaminiana. Cadernos Walter Benjamin, Ceará, v. 6, n. 6, p. 1-12, jan/jul 2011. Disponível em:< http://gewebe.com.br/pdf/cad06/texto_01.pdf> Acesso em: 02 jul. 2012. 